\title{
Impact of data assimilation of physical variables on the spring bloom from TOPAZ operational runs in the North Atlantic
}

\author{
A. Samuelsen, L. Bertino, and C. Hansen \\ Nansen Environmental and Remote Sensing Center, Bergen, Norway \\ Received: 19 December 2008 - Published in Ocean Sci. Discuss.: 19 February 2009 \\ Revised: 31 August 2009 - Accepted: 26 November - Published: 7 December 2009
}

\begin{abstract}
A reanalysis of the North Atlantic spring bloom in 2007 was produced using the real-time analysis from the TOPAZ North Atlantic and Arctic forecasting system. The TOPAZ system uses a hybrid coordinate general circulation ocean model and assimilates physical observations: sea surface anomalies, sea surface temperatures, and sea-ice concentrations using the Ensemble Kalman Filter. This ocean model was coupled to an ecosystem model, NORWECOM (Norwegian Ecological Model System), and the TOPAZNORWECOM coupled model was run throughout the spring and summer of 2007. The ecosystem model was run online, restarting from analyzed physical fields (result after data assimilation) every 7 days. Biological variables were not assimilated in the model. The main purpose of the study was to investigate the impact of physical data assimilation on the ecosystem model. This was determined by comparing the results to those from a model without assimilation of physical data. The regions of focus are the North Atlantic and the Arctic Ocean. Assimilation of physical variables does not affect the results from the ecosystem model significantly. The differences between the weekly mean values of chlorophyll are normally within $5-10 \%$ during the summer months, and the maximum difference of $\sim 20 \%$ occurs in the Arctic, also during summer. Special attention was paid to the nutrient input from the North Atlantic to the Nordic Seas and the impact of ice-assimilation on the ecosystem. The ice-assimilation increased the phytoplankton concentration: because there was less ice in the assimilation run, this increased both the mixing of nutrients during winter and the area where production could occur during summer. The forecast was also compared to remotely sensed chlorophyll, climatological nutrients, and in-situ data. The results show that the model reproduces a re-
\end{abstract}

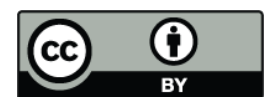

Correspondence to: A. Samuelsen (annette.samuelsen@nersc.no) alistic annual cycle, but the chlorophyll concentrations tend to be between 0.1 and $1.0 \mathrm{mg} \mathrm{chl} / \mathrm{a} / \mathrm{m}^{3}$ too low during winter and spring and $1-2 \mathrm{mg} \operatorname{chl} a / \mathrm{m}^{3}$ too high during summer. Surface nutrients on the other hand are generally lower than the climatology throughout the year.

\section{Introduction}

Marine phytoplankton are important because they make up the base of the food chain that supports the majority of life in the ocean. They also play a key role in the absorption and redistribution of $\mathrm{CO}_{2}$ in the ocean. But algae blooms are not always beneficial; in large quantities they can be harmful to marine life as well as unpleasant to humans. Much of the algae growth in the ocean is controlled by physical variables such as temperature, mixed layer depth, and light. This makes it, in principle, possible to forecast algae concentrations and other water quality parameters (nutrients, oxygen, etc.) on the time-scales from about a week to a month forward in time using a coupled physical-biological model.

In recent years forecasts of physical ocean variables have been improving and operational systems have been established by several partners of the Global Ocean Data Assimilation Experiment (GODAE) (e.g. Drévillon et al., 2008; Hurlburt et al., 2008; Johannessen et al., 2006). Operational systems typically consist of remote and in-situ monitoring in addition to ocean general circulation models (OGCM), providing input to nested coastal forecasting systems, oil-drift models, and biogeochemical models. The establishment of such operational models have largely been made possible thanks to the recent large increase in computing resources. However the capacity of these models to support physicalecosystem models is not fully demonstrated: Berline (2007) showed improvements of ecosystem simulations obtained by

Published by Copernicus Publications on behalf of the European Geosciences Union. 
assimilation of physical data but also recognized the need for a post-processing step to reduce the vertical adjustments of data assimilation. It is however not straightforward to generalize these findings to all data assimilation methods. At the time of writing none of the GODAE forecast systems are run coupled to an ecosystem, but many of them, including the TOPAZ system, are planning its inclusion in the near future in order to feed realistic lateral boundary conditions to coastal ecosystem forecast models. This goal justifies a careful examination of the effects of physical data assimilation in a coupled model. Since the TOPAZ system is the Arctic component of the MERSEA system, this study focuses on the nutrient inflow into the Nordic Seas and the impact of assimilating sea-ice parameters.

The biogeochemical models face an additional challenge compared to the physical models, not only because their numerous biological tracers make them computationally more costly, but also because of the large number of empirical parameters and the scarcity of data available for validation and tuning. A large number of models exists with complexities ranging from simple three-compartment (nutrient, phytoplankton, zooplankton) models that are now mostly used for process studies (e.g. Pasquero et al., 2005) to models with 100 or more state variables (e.g. Allen et al., 2001). There are however practical limits to how many parameters that can be tuned using a sparse biological observation network, and models of intermediate complexity are so far preferable for large-scale simulations.

Here we have performed and evaluated a test forecast for the spring and summer of 2007, the last operational period for the TOPAZ2 system (Bertino and Lisæter, 2008). The primary production model is the Norwegian Ecological Model System (NORWECOM: Skogen and Søiland, 1998) which is coupled online to the TOPAZ forecasting system. In one run the physical system is run with assimilation, this means that the physical model fields are updated every seven days with operational analyzed fields and run one week forward in time as a coupled model, thus providing similar results as if the coupled system had been run in near real-time. We refer to the resulting coupled simulation as a "forecast" although it was produced a posteriori and forced by analyzed atmospheric fields. For reference, a free run without assimilation of physical variables was performed. The two main purposes of the study were (1) to evaluate the impact of assimilation of physical variables on the coupled system and (2) to evaluate the forecast quality.

The evaluation of the forecast itself showed that the seasonal cycle was reasonably well reproduced, however the chlorophyll was systematically underestimated in the winter/spring and over-estimated in the open ocean during summer. Comparison with in-situ data shows that the nutrients in the Faeroe-Shetland channel were realistically reproduced, while the model performance in the North Sea was not good. Elsewhere in the focus region there were no in-situ data available. The assimilation of ice caused both higher nutrient concentration during winter and more phytoplankton during summer. This was caused by a larger ice-free area in the assimilation run.

\section{Methods}

\subsection{Physical model}

The physical model used is the Hybrid Coordinate Ocean Model (HYCOM: Bleck, 2002). In our configuration this model uses isopycnal coordinates in the deep and stratified ocean and z-level coordinates in the upper mixed layer. In the isopycnal space, the vertical velocities are the vertical movements of the isopycnal layers, but not a component of the velocity vector. The KPP (K-Profile Parameterization) mixing scheme is used for the mixed layer (Large et al., 1994). The model is coupled to a sea-ice module consisting of two components; a thermodynamic model (Drange and Simonsen, 1996) and an elastic-viscous-plastic rheology (Hunke and Dukowicz, 1997). Freshwater fluxes from rivers are included as climatological monthly values. The TOPAZ largescale model does not include tides.

For an effective spin-up of the ecosystem model we run the model on a coarse domain ( $\sim 50 \mathrm{~km}$ resolution) in the North Atlantic, hereafter called COARSE. COARSE has 23 layers in the vertical and because this model was intended for coupling to biogeochemical models, the upper 5 layers were defined as z-levels to ensure good resolution in the upper part of the water column. The technical details of the spin-up of this model and the model drift are summarized in Hansen and Samuelsen (2009). The model was initialized with the Generalized Digital Environmental Model Data Base climatology (GDEM: Teague et al., 1990) and run from 1957 to the end of 2005. From January 2006 the runs were switched to the data assimilative model TOPAZ2, which has a higher resolution of $\sim 20 \mathrm{~km}$ in the area of the Norwegian Sea and the Arctic (Bertino and Lisæter, 2008) but still does not resolve eddies in high latitudes. The TOPAZ2 model was initialized from GDEM and spun up for eight years before switching to forecast mode in January 2005. The output from the operational forecast run have been used for the present experiment. TOPAZ2 has 22 layers, which are all hybrid; this means that the vertical resolution close to the surface is not fixed as in COARSE. This should however have little consequence in the weakly stratified high-latitude regions studied here.

The atmospheric forcing used was the 6-hourly ERA40 atmospheric fluxes (Uppala et al., 2005) from 1957 to 2002. In 2002 the forcing was switched to operational analysis from the European Centre for Medium-Range Weather Forecasts (ECMWF) until the end of the experiment.

\subsection{Data assimilation}

The data assimilation technique is the Ensemble Kalman Filter (EnKF: Evensen, 2006) with a dynamic ensemble of 
100 members. The initial ensemble is set up with differences in the distribution of vertical layers and the ensemble is forced with random perturbations of the surface heat and momentum fluxes. One particular aspect of the EnKF is the possibility to rewrite the analysis step as a matrix multiplication to the right of the forecast ensemble (Evensen, 2003). In other terms the analyzed state vectors are combinations of the forecast ensemble members. This has consequences in terms of vertical stability of the water column, in particular in the HYCOM vertical coordinate system: when updating a state variable in the isopycnal domain, the analyzed variable is a combination of ensemble forecasts in the same density layer, thus at the same reference density. In this sense we expect no inversion of the vertical density gradient with the EnKF analysis and use the standard EnKF analysis without any post-processing.

The data assimilated in TOPAZ2 are merged sea level anomalies from Collecte Localisation Satellites (CLS) (Ducet et al., 2000), sea surface temperature (Reynolds data from the National Oceanic and Atmospheric Administration (NOAA)) and remotely sensed ice concentration from the SPECTRAL Sensor Microwave Imager (SSM/I), derived using the NORSEX algorithm (Svendsen et al., 1983). In-situ profiles are not yet assimilated in this version of the TOPAZ system. The result of these forecasts as well as error statistics are updated regularly on the web-page http://topaz.nersc.no.

\subsection{Biological model}

The biological model used is NORWECOM (Skogen and Søiland, 1998; Skogen et al., 1995; Aksnes et al., 1995). This model has been used for several studies in the North Sea (Skogen and Moll, 2000; Skogen et al., 2004) and has also been applied to the Nordic Seas (Skogen et al., 2007). The original version of NORWECOM was coupled to the Princeton Ocean Model, here it has been coupled to HYCOM. The model includes three nutrients; nitrate, phosphate, and silicate and two phytoplankton functional groups; diatoms and flagellates. The model also includes detritus, biogenic silica, and oxygen (Fig. 1). The model assumes fixed cellular N:P:C ratios. The maximum growth rates is a function of temperature and the light- and nutrient dependent growth is formulated as a function of "affinity" (Aksnes and Egge, 1991; Smith et al., 2009) rather that the more common MichaelisMenten kinetics. The nutrient and light dependent growth is modelled using the "law of the minimum" (i.e. the factor that is most limiting sets the growth rate).

Originally, the model also includes yellow matter and suspended particulates matters, but these two variables are omitted because the focus here is on open ocean waters. Most of the parameters from the original model were kept unchanged. We have however set the sinking rate for diatoms, which is variable in the original model, to a constant $1 \mathrm{~m} /$ day. The grazing mortality rate was constant in the original model, here it has been made a linear function of the phytoplank-

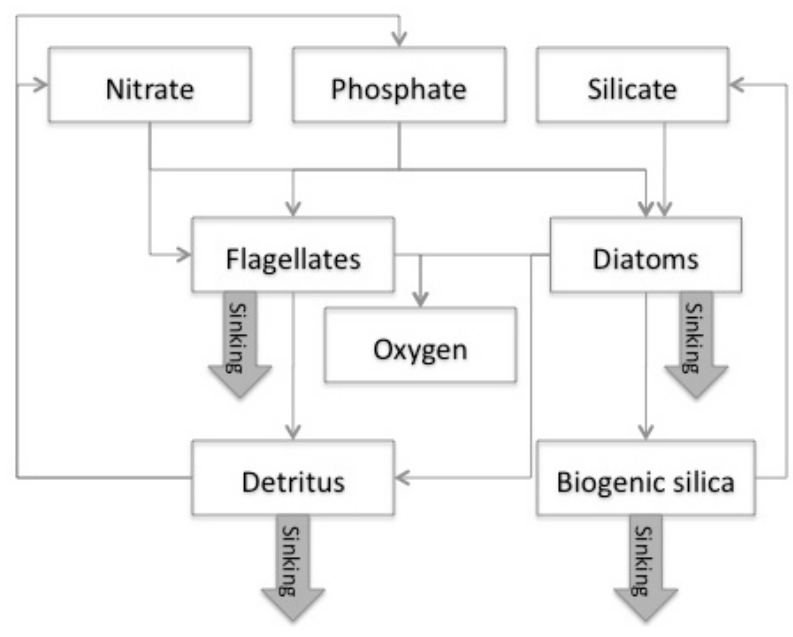

Fig. 1. Overview of the model structure and interaction between model compartments.

ton concentration so that grazing mortality increases with increasing phytoplankton concentrations. This formulation improved the model performance when compared to satellite data (not shown). The parameters that have been changed are listed in Table 1.

The nutrients in the biological model were initiated from Levitus climatology (Conkright et al., 1998). The other variables were initialized with constant low values $\left(0.1 \mathrm{mg} \mathrm{N} / \mathrm{m}^{3}\right.$ for diatoms, flagellates and detritus and $0.1 \mathrm{mg} \mathrm{Si} / \mathrm{m}^{3}$ for biogenic silicate), except for oxygen which was initiated at $4300 \mathrm{mg} \mathrm{O} / \mathrm{m}^{3}$ in the entire domain. The biological variables in COARSE were initialized in 1987 and the coupled model was spun-up until the beginning of 2006. The spin-up was run with monthly climatological nutrients in the rivers, but for simplicity this was omitted in the TOPAZ2 model runs.

The ecosystem variables from COARSE were regridded by bilinear interpolation to the TOPAZ2 model grid and used as initial conditions. Because TOPAZ2 stretches further south than COARSE the values south of $11^{\circ} \mathrm{S}$ are initialized by climatology, while the region between $1^{\circ} \mathrm{S}$ and $11^{\circ} \mathrm{S}$ were initialized with a linear blend of results from COARSE and climatology. The coupled version of TOPAZ2 was then run from January 2006 to January 2007, coupled to the data assimilative operational system. The last model field from this run was used as initial condition for the comparison runs described below. The sequence of steps in the spin-up is summarized in Table 2.

\subsection{Experiment setup}

Two experiments were performed, both were initiated on 2 January 2007 and run until the end of August 2007. In the first experiment the restart files were updated every seven days with the analysis fields from the TOPAZ2 forecast. The second experiment was a free run. 
Table 1. Parameters that have been altered from the original model.

\begin{tabular}{llll}
\hline Parameter & Original value & New value & Comment \\
\hline $\begin{array}{l}W_{\text {dia, } \min } \\
W_{\text {dia, max }}\end{array}$ & $\begin{array}{l}0.3 \mathrm{~m} / \text { day } \\
3 \mathrm{~m} / \text { day }\end{array}$ & $\begin{array}{l}1.0 \mathrm{~m} / \text { day } \\
1.0 \mathrm{~m} / \text { day }\end{array}$ & $\begin{array}{l}\text { The diatom sinking rate in the origi- } \\
\text { nal model increased with decreasing sil- } \\
\text { icate concentration, it is constant in this } \\
\text { simulation. }\end{array}$ \\
$m_{\text {phy }}$ & $1.16 \times 10^{-6} \mathrm{~s}^{-1}$ & $\begin{array}{l}7.7 \times 10^{-8} \mathrm{Phy} \\
\mathrm{s}^{-1} \mathrm{~g} \mathrm{~N}^{-1} \mathrm{~m}^{3}\end{array}$ & $\begin{array}{l}\text { The phytoplankton growth rate has been } \\
\text { changed from a constant to a function of } \\
\text { phytoplankton concentration (Phy). }\end{array}$ \\
& & &
\end{tabular}

Table 2. The timeline of the model run.

\begin{tabular}{ll}
\hline Month, Year & Event \\
\hline January, 1957 & $\begin{array}{l}\text { The physical part of COARSE is initial- } \\
\text { ized with climatological values. } \\
\text { The physical part of TOPAZ2 initial- } \\
\text { January, 1987 from climatological values. } \\
\text { January, 1987 }\end{array}$ \\
$\begin{array}{l}\text { The ecosystem module is initialized in } \\
\text { COARSE. }\end{array}$ \\
January, 2005 & $\begin{array}{l}\text { The assimilation of physical data is ini- } \\
\text { tiated in TOPAZ2. } \\
\text { The TOPAZ2 model is initialized } \\
\text { with interpolated ecosystem fields from } \\
\text { January, 2007 }\end{array}$ \\
& $\begin{array}{l}\text { Start of the free versus assimilation } \\
\text { comparison study. }\end{array}$ \\
\hline
\end{tabular}

\section{Results}

The model was divided into five regions for assessment (Fig. 2). Region I is the region from $70^{\circ} \mathrm{W}$ to $20^{\circ} \mathrm{W}$ and $50^{\circ} \mathrm{N}$ to $60^{\circ} \mathrm{N}$, it contains mostly polar water-masses south of Greenland, but there are also some warm Atlantic water masses present in the eastern part. Region II stretches from $20^{\circ} \mathrm{W}$ to $20^{\circ} \mathrm{E}$ and $50^{\circ} \mathrm{N}$ to $60^{\circ} \mathrm{N}$, it includes the waters surrounding the British Isles and the North Sea and is dominated by warm Atlantic water masses. Region III is from $50^{\circ} \mathrm{W}$ and $10^{\circ} \mathrm{W}$ and $60^{\circ} \mathrm{N}$ and $70^{\circ} \mathrm{N}$ and covers the Iceland Sea, while region IV represents the Norwegian Sea and stretches from $10^{\circ} \mathrm{W}$ and $20^{\circ} \mathrm{E}$ and $60^{\circ} \mathrm{N}$ and $70^{\circ} \mathrm{N}$. Region III has both Atlantic and Arctic water masses, while region IV has primarily Atlantic water masses. Region $\mathrm{V}$ is from $25^{\circ} \mathrm{W}$ and $60^{\circ} \mathrm{E}$ and $70^{\circ} \mathrm{N}$ and $80^{\circ} \mathrm{N}$ and contains the Barents Sea and the Greenland Sea and is dominated by Arctic water masses. In Sect. 3.1 the general results from the model are described, based on the model run with assimilation. In Sect. 3.2 the forecast of chlorophyll is evaluated based on a comparison of the run with assimilation and observations from the Moderate Resolution Imaging Spectro-

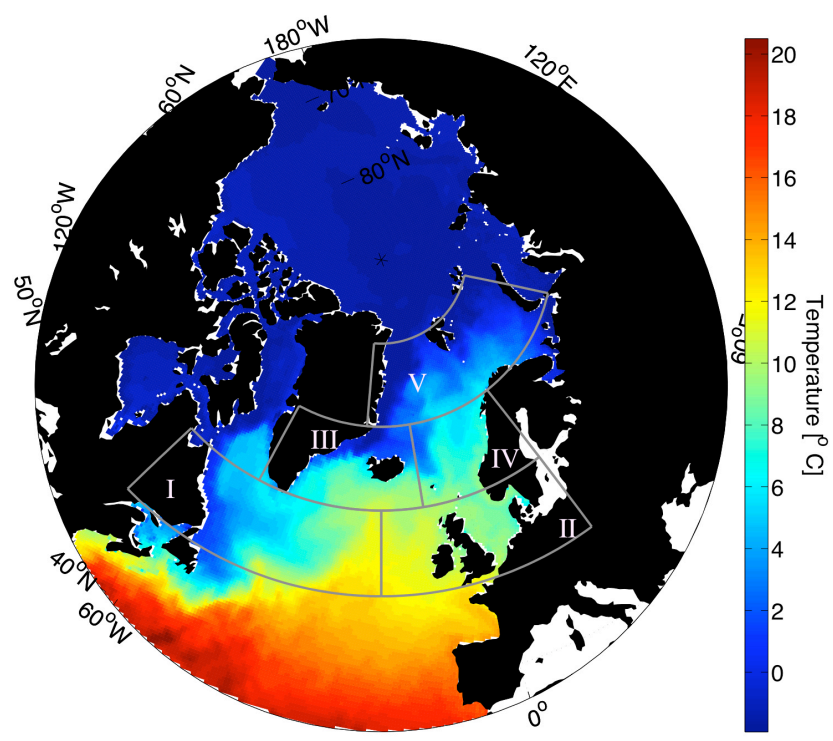

Fig. 2. The five areas that were selected as focus areas superimposed on the temperature averaged over the upper $100 \mathrm{~m}$ in January 2007 in the model run with assimilation. In areas where the total depth is less than $100 \mathrm{~m}$, the temperature is averaged over the water column.

radiometer (MODIS), while in Sect. 3.3 the two runs with and without assimilation are compared to study the effect of assimilation of physical variables on the ecosystem model.

\subsection{General performance}

The general performance of the model was evaluated by comparing the model nutrients to monthly climatologies (Conkright et al., 1998). This is unfortunately not an independent data set since the model was initiated with the climatological nutrient. In addition, the model is expected to deviate from climatology as it resolves interannual variability, but large discrepancies can be indications of model errors. We have defined "large" discrepancy as $2.5 \mu \mathrm{M}$ for nitrate, $2.0 \mu \mathrm{M}$ for silicate, and $0.15 \mu \mathrm{M}$ for phosphate. The monthly chlorophyll concentrations were compared to 

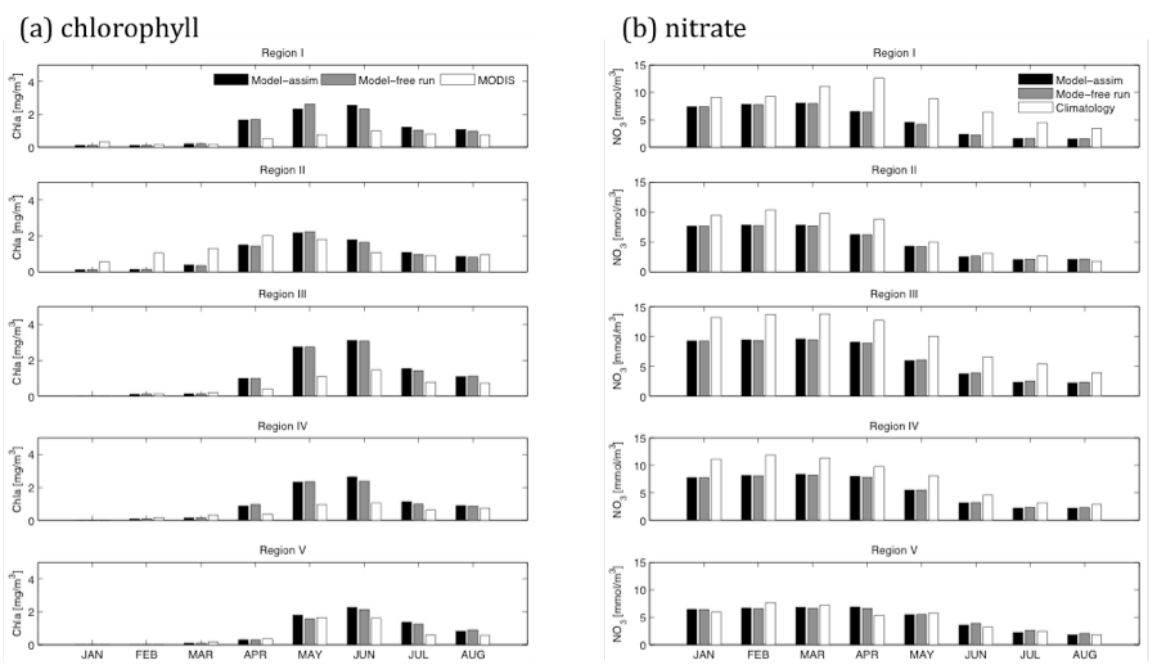

(c) silicate
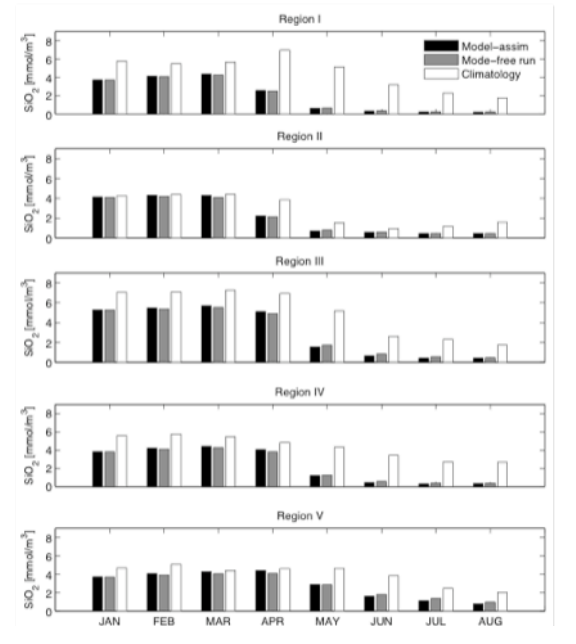

(d) phosphate
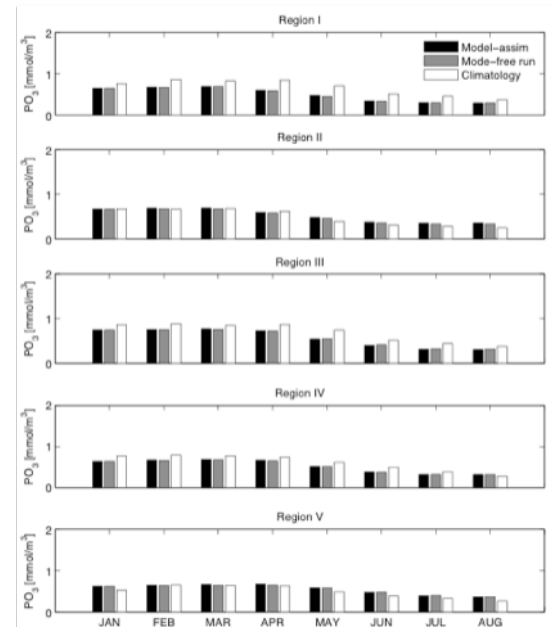

Fig. 3. Monthly mean values for (a) chlorophyll from the assimilation run (black), the free run (gray), and MODIS (white). Monthly mean values for (b) nitrate, (c) silicate, and (d) phosphate for the assimilation run (black), free run (gray), and climatology (white). The modelled chlorophyll concentrations are averaged over the upper $30 \mathrm{~m}$, while the nutrients, both modelled and climatological are averaged over the upper $50 \mathrm{~m}$.

monthly chlorophyll values from MODIS. For comparison with satellite-derived chlorophyll we consider a relative bias of less than $30 \%$ as good.

The model reproduced the annual cycle in all five regions (Fig. 3), but particularly in regions I, III, and IV there are rather large errors. In general the chlorophyll values are realistic with errors less than $0.2 \mathrm{mg}$ chl $a / \mathrm{m}^{3}$ prior to the spring bloom, the exception is region II, the North Sea, where it is underestimated by about $1.0 \mathrm{mg} \operatorname{chl} a / \mathrm{m}^{3}$ (Fig. 4). During summer, the bias is less than $1.0 \mathrm{mg} \operatorname{chl} a / \mathrm{m}^{3}$ in region II and IV, but up to $2.0 \mathrm{mg} \operatorname{chl} \mathrm{a} / \mathrm{m}^{3}$ in the other regions. Compared to climatology most nutrients are underestimated in all five regions. The phosphate bias is generally low, the same is the case for the silicate concentrations during summer. Nitrate is also $4-6 \mathrm{mmol} / \mathrm{m}^{3}$ too low in region I during summer and in region III and IV during winter.

\subsection{Forecast evaluation}

The forecast was evaluated using 8-day composite images from MODIS, in addition, nutrients and chlorophyll were compared to available in-situ data from ICES. The data were compared to weekly averages from the model in overlapping periods. Because the model is not designed for coastal areas, all data from waters with depth less than $100 \mathrm{~m}$ have been removed, but the ICES data were still most frequent in regions close to land. There were no in-situ data in regions I, III, and $\mathrm{V}$ between January and August of 2007, but there was good 
(a) chlorophyll

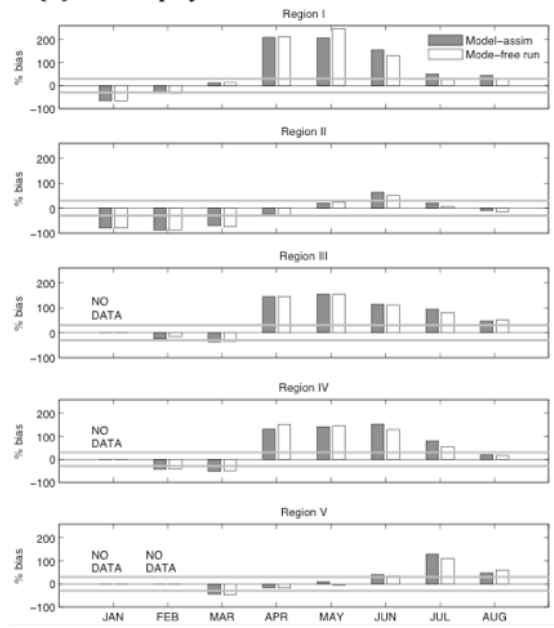

(c) silicate
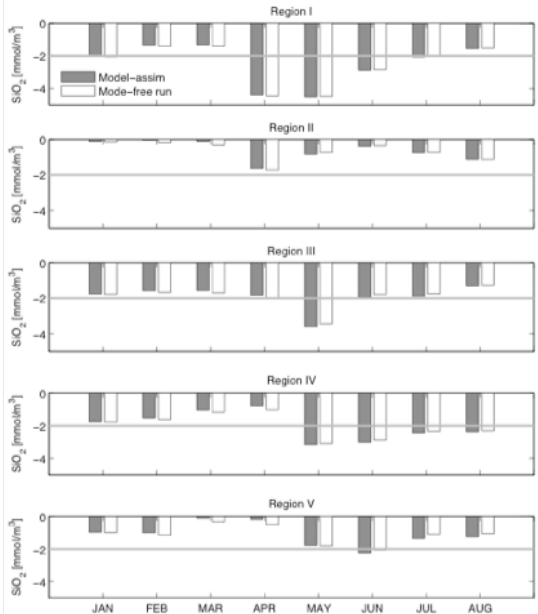

(b) nitrate
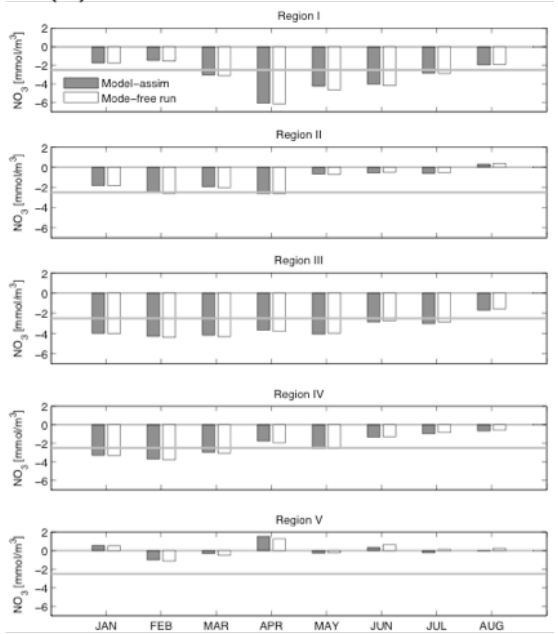

(d) phosphate
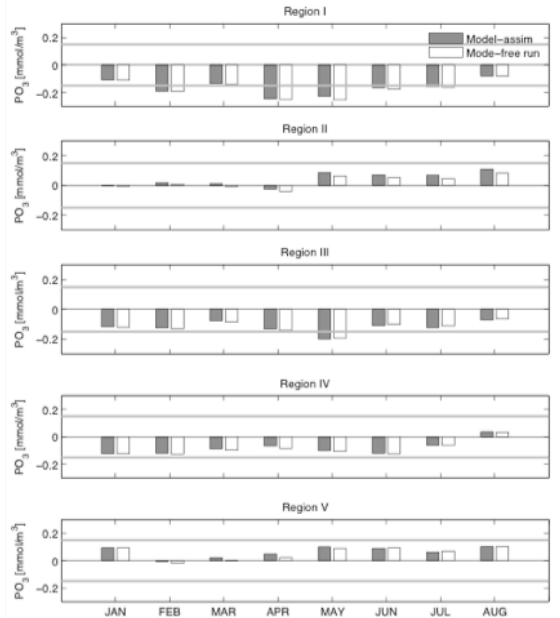

Fig. 4. Monthly error statistic for the model in each of the 5 regions for the assimilation run (gray) and free run (white). (a) Monthly modelled chlorophyll values are compared to monthly composits from MODIS. The gray line indicates a percent bias of 30 . The nutrients have been compared to monthly climatologies and the bias between the monthly values have been computed. The values here were integrated over the upper $50 \mathrm{~m}$ : the gray lines indicate (b) $2.5 \mu \mathrm{M}$ nitrate, (c) $2.0 \mu \mathrm{M}$ silicate, and (d) $0.15 \mu \mathrm{M}$ phosphate.

data coverage in the North Sea - where only the Skagerrak and the Norwegian Trench are deep enough to be considered in this comparison. In the Faroe-Shetland channel data were available from May only.

The comparisons between weekly satellite data and model results are frequently obstructed by clouds and during the winter months the areas farthest north are unavailable from the satellite because the sun is too low. Figure 5 shows some relatively cloud-free examples from different regions and times of the year. The model frequently overestimates the open-ocean chlorophyll values as was previously indicated by the comparison with monthly data. In region II the chlorophyll concentrations east of the British Islands are usually underestimated, while west of the British Islands they are frequently overestimated. In general, for all regions, the chlorophyll concentrations in May and June are overestimated, while in July and August they are good. The coastal chlorophyll concentrations were often underestimated in all seasons. The satellite data are patchier than the model results which are quite smooth due to the lack of grid resolution. The model has a well-defined bloom along the ice-edge. Unfortunately this bloom was not visible in the satellite data because of the cloud cover, but it is a well-known phenomena (Engelsen et al., 2002; Sakshaug et al., 1992).

Comparison with the ICES data from the North Sea shows that nutrients are generally too low in the Skagerrak, particularly in the surface waters during winter. The in-situ data indicate that the nutrient concentrations increase towards the bottom, while the modelled nutrient-concentration is uniform below $200 \mathrm{~m}$. The spring bloom starts later than what is 

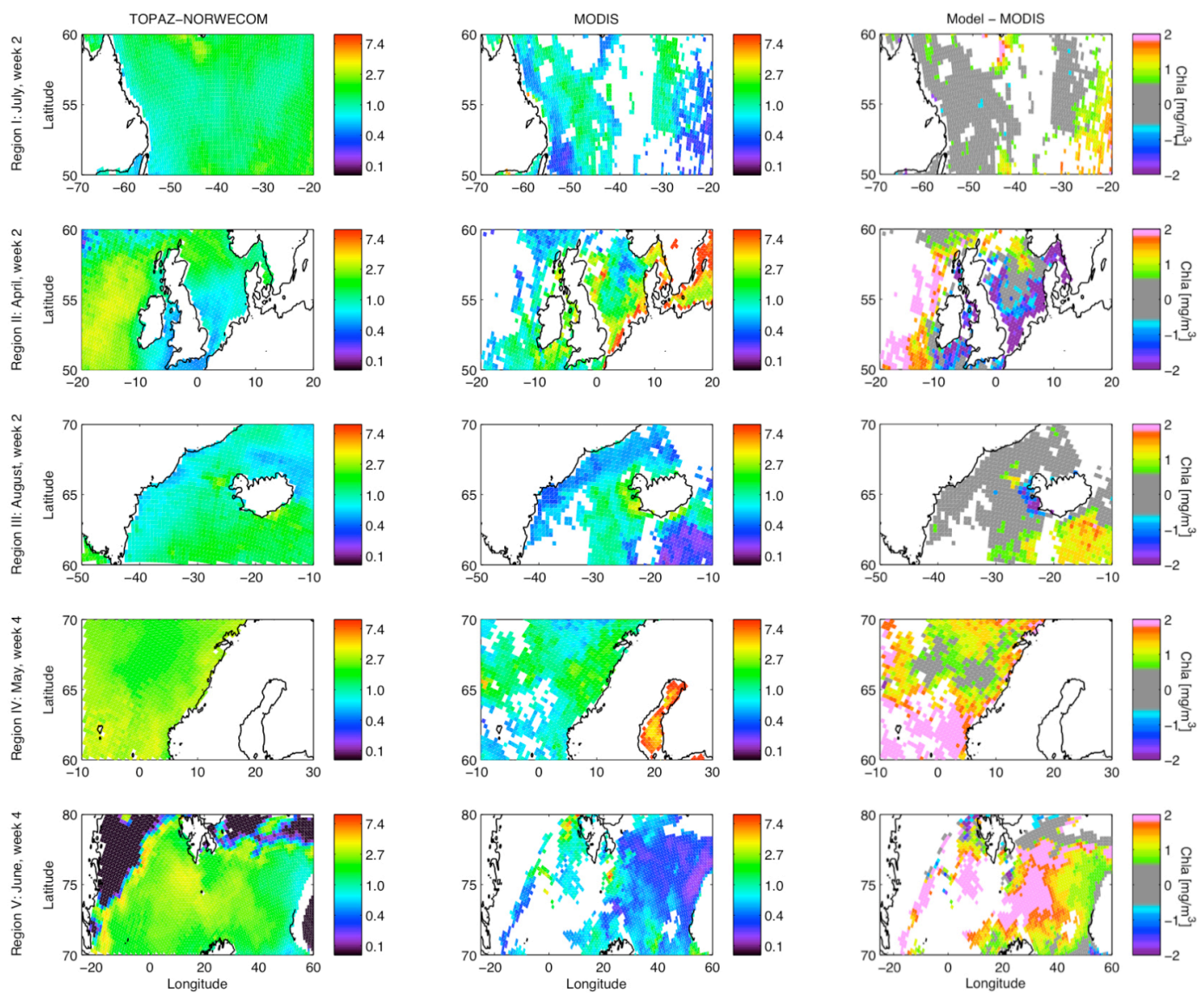

Fig. 5. Comparison between weekly model estimates and MODIS chlorophyll in the five regions. The regions were selected according to times when there was little cloud cover (region I: July, week 2, region II: April, week 2, region III: August, week 2, region IV: May, week 4, and region V: June, week 4). The first column shows the model results, the second column shows the MODIS data, and the third column shows the difference between the two. The gray regions in the third column are areas where the difference is less that $0.6 \mathrm{mg} \mathrm{Chl} / \mathrm{m}^{3}$.

observed and both nutrient and chlorophyll profiles indicate that the modelled water column has a deeper mixed layer than the observed. The observed data around the Norwegian trench were too sparse to make any conclusion about the model performance. The North Sea is heavily influenced by nutrient input from large rivers such as the Elbe, and we do not expect this model to perform well here because river nutrients are excluded in this model simulation. The model performs rather well in the Faroe-Shetland channel (Fig. 6), the general distribution of nutrients is reproduced even if the model tends to overestimate the concentration in the deep western part of the channel while it is too low at the surface. In the Faroe-Shetland Channel the vertical nutrient profiles indicate that the modelled water-column is less mixed than in observations, contrary to the Skagerrak.

\subsection{Effect of assimilation}

The effect of assimilation on the physical model variables was evaluated by comparing the model results to the ICES in-situ temperature and salinity data (available from http://
www.ices.dk/ocean/aspx/HydChem/HydChem.aspx). In region I and III there were too few data points to make a comparison. In region II, the North Sea (Table 3), the temperature is improved in the assimilation run, from May onward the correspondence between both the free-run and the assimilation runs are remarkably good. The effect of the assimilation on the salinity in the North Sea is small and we see little improvement on this variable. In the Norwegian Sea (Table 3), region IV, the temperature deteriorate compared to the data in the assimilation run during winter, but improve later in the spring and summer. It is unclear if the increasing error in winter is an effect of the assimilation or the data being assimilated. The temperature dataset assimilated is based primarily on satellite, and supplemented with sea-ice, ship, and buoy data when available (Reynolds et al., 2002). Where there are no observations spatial interpolation is used. The Norwegian Sea is frequently covered by clouds during winter and it is therefore likely that satellite data was sparse during this period, the ship and buoy data coverage is not known. The salinity in region IV, which is generally 

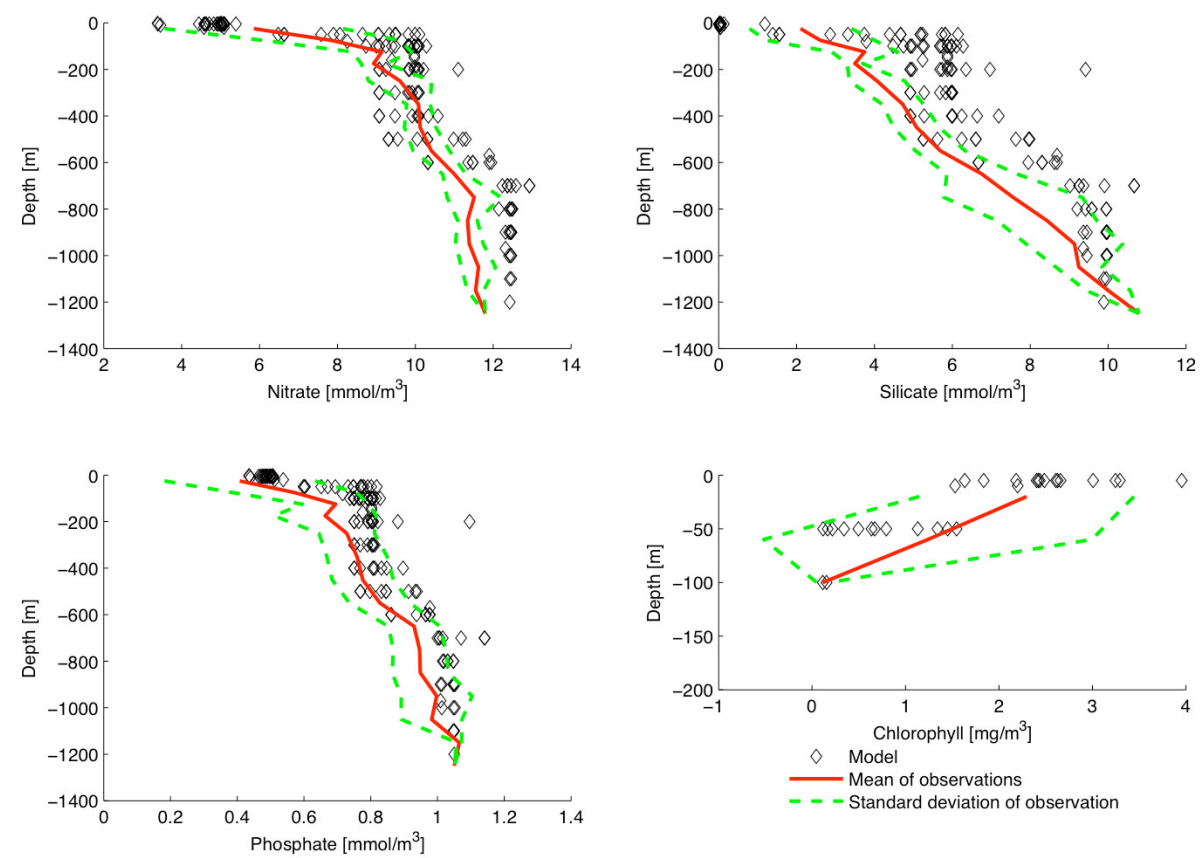

Fig. 6. Comparison between the model results and the in-situ data in the Faroe-Shetland channel in May 2007. The red line shows the horizontal mean of the in situ at specific depths, the green dotted lines show the standard deviation, and the black diamonds are the model results extracted at the observation points.

Table 3. Bias for temperature $\left({ }^{\circ} \mathrm{C}\right)$ compared to the ICES data in region II and IV.

\begin{tabular}{lcccc}
\hline Month & \multicolumn{2}{c}{$\begin{array}{c}\text { Region II - North Sea } \\
\text { Assimilation run }\end{array}$} & Free run & \multicolumn{2}{c}{ Region IV - Norwegian Sea } \\
& Assimilation run & Free run \\
\hline January & 0.19 & 0.35 & -0.13 & -0.12 \\
February & 0.31 & 0.56 & -0.74 & -0.45 \\
March & 0.09 & -0.08 & -0.92 & -0.41 \\
April & -0.09 & 0.30 & -0.68 & -0.29 \\
May & 0.06 & 0.27 & -0.02 & 0.27 \\
June & -0.11 & 0.08 & -0.03 & 0.38 \\
July & -0.02 & 0.19 & -0.16 & 0.13 \\
August & -0.09 & 0.25 & -0.2 & 0.13 \\
\hline
\end{tabular}

too fresh in the model, is improved in the assimilation run in the Norwegian Sea. In the Norwegian Sea, surface waters are warmer and fresher than the waters below. Since the ensemble perturbations influence the water stratification, the temperature and salinity are negatively correlated and the negative temperature updates increase the surface salinity. In region $\mathrm{V}$, where there is also assimilation of ice, the salinity is improved while the temperature is slightly worse. Here the majority of the measurements are in the Barents Sea. When comparing profiles it becomes clear that although the assimilation decreases the overall model errors, it does not necessarily produce a more realistic stratification. This may be because only surface data were assimilated.
Of particular interest was the effect of the assimilation of ice on the ecosystem model results. To our knowledge, this is the first coupled physical-ecosystem model that is run with sea-ice assimilation. Region $\mathrm{V}$ is the only region where there are large amounts of ice - although small amounts of ice occur in region I and III - therefore we will focus on region V. The primary effect of assimilation was a reduction in the ice area of roughly $10 \%$ compared to the free run (Fig. 7a). This had a double effect on the ecosystem. First, during winter a larger open ocean area was exposed to the wind, therefore allowing for more nutrients to be mixed up during winter and causing higher surface concentrations (Fig. 7c). Second, it leaves a larger area exposed to sunlight during spring and summer, this combined with higher nutrient concentration at 

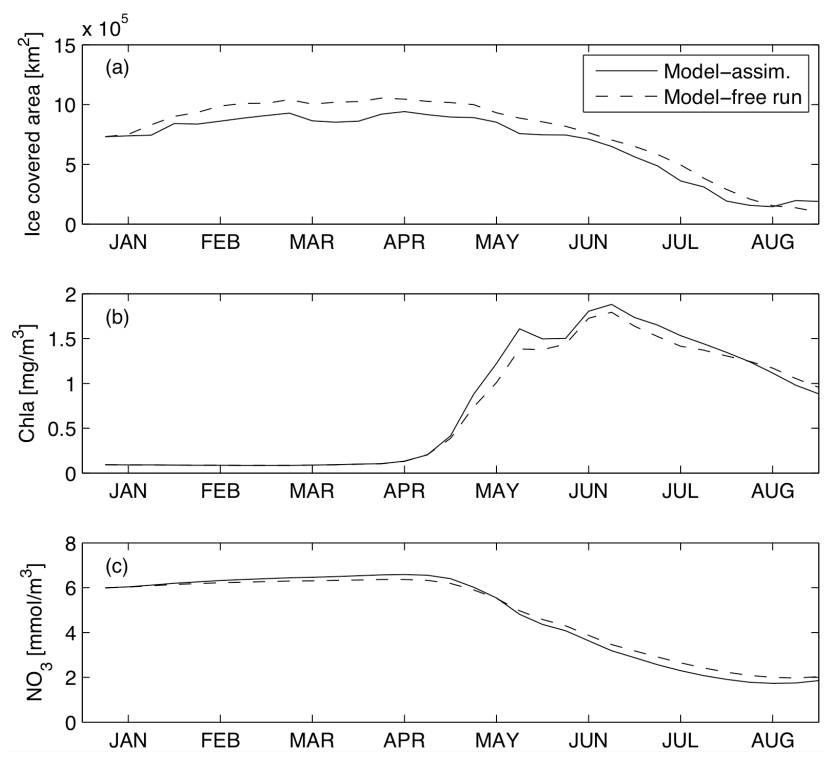

Fig. 7. The effect of assimilation of ice in region $\mathrm{V}$, the assimilation run is plotted as a solid line and the free run as a dashed line. (a) Ice area, (b) mean chlorophyll concentration, and (c) mean nitrate concentration in region $\mathrm{V}$ from weekly averages. The chlorophyll concentration is depth-averaged over the upper $30 \mathrm{~m}$, while the nitrate concentration is depth-averaged over the upper $50 \mathrm{~m}$.

the surface causes a larger phytoplankton concentration in the assimilation run (Fig. 7b). The ice-edge bloom was more diffuse in the assimilation run than the free run, this is probably caused by the ice-edge "moving" abruptly with the assimilation updates. Regionally, the assimilation of ice moves the ice-edge northward in the Greenland Sea and southward in the Barents Sea, this means that the Barents Sea becomes less productive, while the primary production in the Greenland Sea increases with assimilation.

The overall effect of assimilation was generally small. For chlorophyll there was a 5-10\% difference during summer, usually with the assimilation run having the highest concentrations. The maximum difference $(\sim 20 \%)$ occurred in region $\mathrm{V}$ in May. Compared to the satellite and climatological data the performance of the model runs was roughly equal (Fig. 4), there are small differences in space and time, but no clear indication of one being better than the other.

The mixed layer was on average deeper in the assimilation run in region III, VI, and V, while it was shallower in region I. In region II, which is relatively shallow on average, the mixed layer depth was roughly unchanged. It is expected that the winter nutrient concentrations are higher in regions with a deeper winter-mixed-layer, however, the winter nutrient concentrations in the assimilation run are higher in all five areas. The nutrient concentrations are between 2 and $8 \%$ higher than the free run (Fig. 8). The assimilation run therefore brings up more nutrients during winter than the free run and this may be a different effect of assimilation, either by
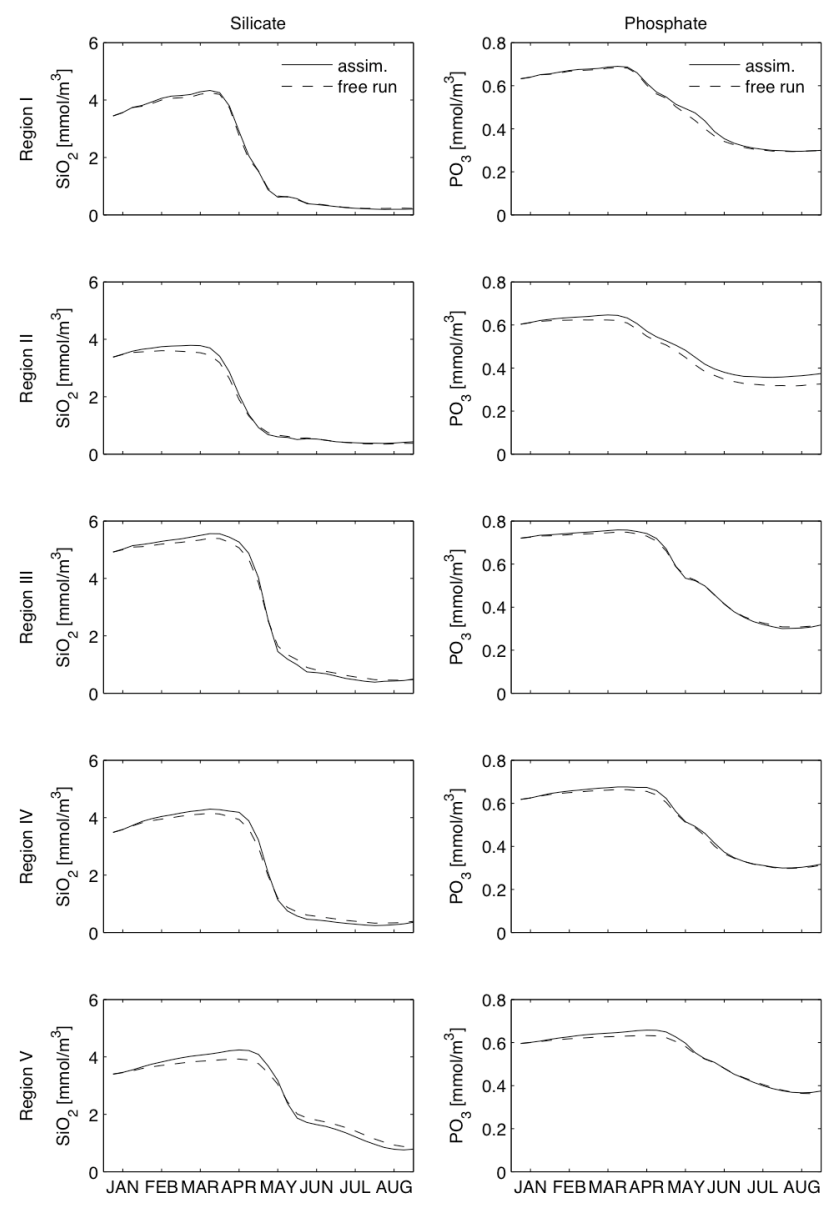

Fig. 8. Comparison between weekly averaged nutrients in the assimilation run (solid line) and the free run (dashed line): silicate (first column) and phosphate (second column) in the five regions. The nutrients have been depth-averaged over the upper $50 \mathrm{~m}$.

vertical or horizontal advection. The differences are largest in frontal areas, probably due to vertical movement of the isopycnals. During summer the concentrations are generally lower in the assimilation run, this is a result of higher primary production.

As an effect of the increased nutrient availability, the spring bloom, which consists mainly of diatoms, and the later flagellate bloom both have higher maxima (Fig. 9) in the assimilation run. The timing of bloom remains unchanged, except for the flagellate bloom in region I, which is later in the assimilation run. This is probably because the mixed layer shoals earlier in the free run in region I during the onset of this bloom (not shown).

\section{Discussion}

We have performed a simili-forecast of the spring and summer of 2007 using a coupled physical biological model for the North Atlantic and Arctic. The forecast was compared 

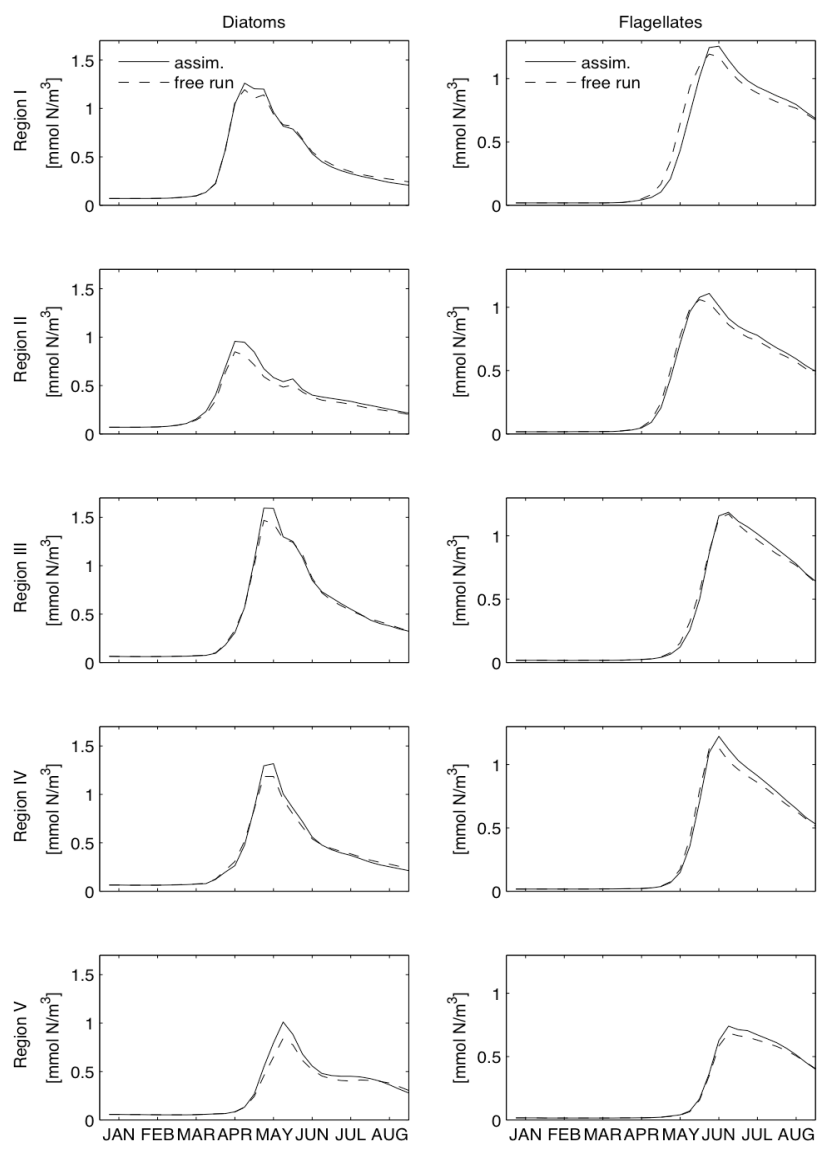

Fig. 9. Comparison between phytoplankton in the assimilation run (solid line) and the free run (dashed line): diatoms (first column) and flagellates (second column) in the five regions. The phytoplankton have been depth-averaged over the upper $50 \mathrm{~m}$.

to climatology, satellite-derived chlorophyll, and in-situ data. The comparison showed that the general annual cycle was reproduced (Fig. 3), however the model underestimated chlorophyll during winter while it overestimated chlorophyll during summer (Fig. 4). The negative bias in the nutrients throughout the simulation period (Fig. 4) excluded excess nutrients as a cause for the high summer chlorophyll concentration. There are two other likely possibilities: the first is a too high phytoplankton production that make the phytoplankton consume too much nutrients. The second possibility is that the lack of grazers in the model (grazing mortality is parameterized) causes the consumption of phytoplankton by zooplankton to be underestimated during summer. This will in turn cause surface nutrients to be more depleted. The summer overestimation is most likely caused by too low mortality as the summer nutrient concentrations are substantially lower than the climatology. The model is not expected to reproduce the climatology exactly, but, considering that the results were averaged over large areas (Fig. 2), the differences are both large and consistent between regions (Fig. 4). This indicates that the differences are not caused by interannual variability.
When compared to satellite images from MODIS, the model chlorophyll was frequently under-estimated in coastal and shallow regions even if it was over-estimated in the open ocean. The current model is not optimized for coastal regions and one of the aims of this forecast system is that it should provide nesting conditions (both physical and biological) to a coastal model. Therefore this models performance in the coastal regions is not a priority. The model results are also much smoother than the satellite data (Fig. 5), this is largely caused by the lack of eddy resolution (Hansen and Samuelsen, 2009). In addition the satellite images are not weekly averages, but a composite of incomplete satellite passes obtained that week.

The in-situ data were only available in the North Sea and the Faroe-Shetland channel. In the North Sea the model performs poorly because river nutrient inputs are missing and the model is not configured for this area. The nutrient and chlorophyll profiles indicated that the modelled water column is mixed deeper than in the observations. Excess mixing was also noticed by Winther and Evensen (2006). Comparison to a section across the Faeroe-Shetland channel showed that the model results were realistic there. The upper profile indicated that the water column here was on the contrary less mixed in the model than the observations (Fig. 6). This could be because the model does not include tides, which would increase the mixing in areas with steep bathymetry such as in the channel between these two island groups. About half of the inflow to the Norwegian Sea occurs in the Faroe-Shetland channel (Hansen and Østerhus, 2000) and realistic concentrations here indicate that the nutrient concentrations in the water masses entering the Norwegian Sea are reasonable.

The assimilative run was also compared to a free-run in the same period in order to investigate the effect of the assimilation of physical variables on the results from the ecosystem model. Assimilation did not have a dramatic influence on the ecosystem model, but the run with assimilation consistently had higher nutrient concentration than the free-run. This could not be attributed to differences in the winter mixed layer depth and because the largest differences occur in frontal areas it is likely connected to vertical advection. Differences in horizontal advection may become more important if the comparison is run over a longer period than the current 8 months. The largest differences in chlorophyll concentration were in region $\mathrm{V}$ where assimilation of ice caused the ice-covered area to be smaller both during summer and winter. In the other areas the difference was between 5 and $10 \%$, but no consistent bias could be noticed. In this experiment it is not possible to differentiate between the effect of sea-ice assimilation and that of other physical variables. However, spatial plots of region V (not shown) show that the largest increase in both nutrients and phytoplankton occur in the regions where the assimilation has removed the ice cover. Compared to climatological data and MODIS chlorophyll (Fig. 4) there was no difference between the performance of the free-run and the assimilation 


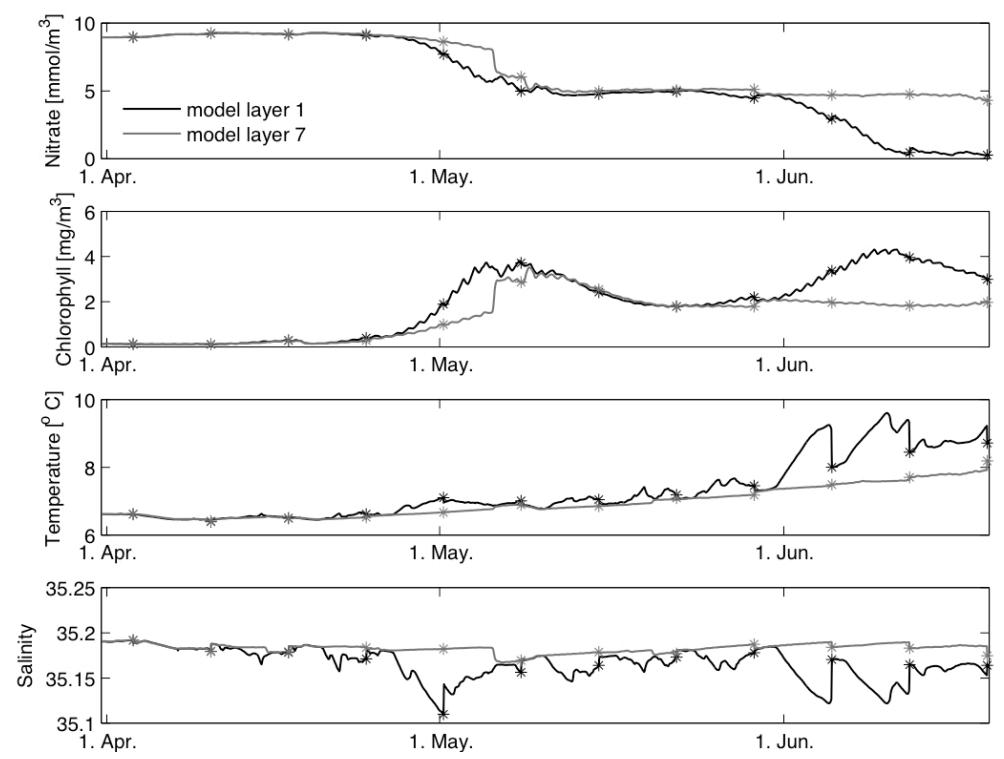

Fig. 10. Time series located at $0^{\circ} \mathrm{W}, 65^{\circ} \mathrm{N}$, showing nitrate, chlorophyll, temperature, and salinity in model layer 1 and 7 in the assimilation run. The update times are indicated by stars and it is clear that although there are large corrections on the temperature and salinity fields, there are no large responses in the nitrate and chlorophyll fields. Layer 1 is located between the surface and $3 \mathrm{~m}$ and layer 7 is between 24.7 and $30.7 \mathrm{~m}$. Both of these layers remain z-layers throughout the simulation at this location.

run. Berline et al. (2007) showed that assimilation of physical variables can lead to spurious mixing. However, after modifying the assimilation routine, they obtained improved results from the biogeochemical model as a result of the assimilation of physical data. The assimilation method used here showed no sign of causing unintentional mixing of nutrients, but it did not improve the biological model results either. Because the state variables are updated in the isopycnal domain after assimilation, the assimilation should not lead to unstable water-masses (Evensen, 2003). However this is not guaranteed in the mixed layer where the coordinates are z-level. Time series from the mixed layer (Fig. 10) shows that there is no "shock" to the ecosystem as a result of the assimilation which indicates that the instabilities are effectively small. The improvements observed by Berline et al. (2007) were most prominent at mid-latitude and particularly connected to improved placement of the Gulf Stream, an area not investigated here. A possible explanation is that the Gulf Stream is a biologically important ocean feature that is resolved by both the model and the data assimilated in study by Berline et al. (2007) and therefore was significantly improved by assimilation. The only such feature in our region of interest is the ice extent. Unfortunately, the data available in this region are to few to decide if the biological model performed better with assimilation.

This model will be set up for operational forecasting in the Atlantic and Arctic Ocean. The primary weakness of the ecosystem model seems to be the grazing formulation and not the physical framework. That there is no significant improvement in the error statistics of COARSE compared to
TOPAZ2 (not shown) supports this conclusion. Model resolution has been shown to impact the results of the biological model, but only when the resolution reaches the point when eddies are resolved (Hansen and Samuelsen, 2009). Therefore the first efforts will be towards finding alternative formulations that improve the model performance. Models without zooplankton compartments do not necessarily perform worse than those with zooplankton compartments (Friedrichs et al., 2007), therefore efforts will be aimed at finding an alternative parameterization rather than adding compartments. The performance in the tropics has not been evaluated here and will be investigated later, but poor performance in the tropics may influence nutrient holding in northern region.

Having an ensemble of physical states in the TOPAZ system opens perspectives for running an EnKF also for the ecosystem model with assimilation of satellite ocean colour data. A preliminary demonstration has used the MICOM model (Natvik and Evensen, 2003b, a) and is now being updated with the HYCOM model (Simon and Bertino, 2009). A practical advantage is that the same physical ensemble can be used as input to the ecosystem data assimilation, allowing a consistent assessment of the model errors for their impact both on physical and on biological variables. A reanalysis is also planned with a higher resolution prototype of the TOPAZ system (TOPAZ3, $11 \mathrm{~km}$ to $16 \mathrm{~km}$ resolution, about $1 / 8$ th of a degree), which is the real-time system operating at time of writing. This would provide an eddy permitting physical system in the Nordic Seas that will be used for coupled physical-ecosystem analysis and forecasts in the future. 
Acknowledgements. This work is partially funded by the European 6th Framework Programme Integrated Project, MERSEA, contract number SIP3-CT-2003-502885 and a private donation from Trond Mohn C/O Frank Mohn AS, Bergen. A grant of computer time from the Norwegian High Performance Computing Project NOTUR has also been used. The authors acknowledge the MODIS Science team for the Science Algorithms, the Processing Team for producing MODIS data, and the GES DAAC MODIS Data Support Team for making MODIS data available to the user community. We are also grateful to the International Council for the Exploration of the Sea for distibuting the ICES Dataset on Ocean Hydrography.

Edited by: N. Pinardi

\section{References}

Aksnes, D. L. and Egge, J. K.: A theoretical model for nutrient uptake in phytoplankton, Marine Ecology-Progress Series, 70, 65-72, 1991.

Aksnes, D. L., Ulvestad, K. B., Balino, B. M., Berntsen, J., Egee, J. K., and Svendsen, E.: Ecological modeling in coastal waters - towards predictive physical-chemical-biological simulationmodels, Ophelia, 41, 5-36, 1995.

Allen, J. I., Blackford, J., Holt, J., Proctor, R., Ashworth, M., and Siddorn, J.: A highly spatially resolved ecosystem model for the North West European Continental Shelf, Sarsia, 86, 423-440, 2001.

Berline, L., Brankart, J.-M., Brasseur, P., Ourmieres, Y., and Verron, J.: Improving the physics of a coupled physical-biogeochemical model of the North Atlantic through data assimilation: Impact on the ecosystem, J. Mar. Syst., 64, 153-172, 2007.

Bertino, L. and Lisæter, K. A.: The TOPAZ monitoring and prediction system for the Atlantic and Arctic Oceans, J. Oper. Oceanogr., 2, 15-18, 2008.

Bleck, R.: An oceanic general circulation model framed in hybrid isopycnic-Cartesian coordinates, Ocean Modell., 4, 55-88, 2002.

Conkright, M. E., Levitus, S., O’Brien, T., Boyer, T. P., Stephens, S., Johnson, D., Stathoplos, L., Baranova, O., Antonov, J., Gelfeld, R., Burney, J., Rochester, J., Forgy, C., and World Ocean Database: Documentation and quality control, National Oceanographic Data Center, Silver Spring, MD, 1998.

Drange, H. and Simonsen, K.: Formulation of air-sea ?uxes in the ESOP2 version of MICOM, Nansen Environmental and Remote Sensing Center, Bergen, 1996.

Drévillon, M., Bourdalle-Badie, R., Derval, C., Drillet, Y., Lellouche, J. M., Remy, E., Tranchant, B., Benkiran, M., Greiner, E., Guinehut, S., Verbrugge, N., Garric, G., Testut, C. E., Laborie, M., Nouel, L., Bahurel, P., Bricaud, C., Crosnier, L., Dombrowsky, E., Durand, E., Ferry, N., Hernandez, F., Galloudec, O. L., Messal, F., and Parent, L.: The GODAE/MercatorOcean global ocean forecasting system: results, applications and prospects, J. Oper. Oceanogr., 1, 51-57, 2008.

Ducet, N., Le Traon, P. Y., and Reverdin, G.: Global high-resolution mapping of ocean circulation from TOPEX/Poseidon and ERS-1 and-2, J. Geophys. Res.-Oceans, 105, 19477-19498, 2000.

Engelsen, O., Hegseth, E. N., Hop, H., Hansen, E., and FalkPetersen, S.: Spatial variability of chlorophyll-a in the Marginal Ice Zone of the Barents Sea, with relations to sea ice and oceanographic conditions, J. Mar. Syst., 35, 79-97, 2002.
Evensen, G.: The Ensemble Kalman Filter: theoretical formulation and practical implementation, Ocean Dynam., 53, 343-367, 2003.

Evensen, G.: Data Assimilation: The Ensemble Kalman Filter, Springer, Heidelberg, 2006.

Friedrichs, M. A. M., Dusenberry, J. A., Anderson, L. A., Armstrong, R. A., Chai, F., Christian, J. R., Doney, S. C., Dunne, J., Fujii, M., Hood, R., McGillicuddy, D. J., Moore, J. K., Schartau, M., Spitz, Y. H., and Wiggert, J. D.: Assessment of skill and portability in regional marine biogeochemical models: Role of multiple planktonic groups, J. Geophys. Res.-Oceans, 112, CO8001, doi:10.1029/2006JC003852, 2007.

Hansen, B. and Østerhus, S.: North Atlantic-Nordic Seas exchanges, Prog. Oceanogr., 45, 109-208, 2000.

Hansen, C. and Samuelsen, A.: Influence of horizontal model grid resolution on the simulated primary production in an embedded primary production model in the Norwegian Sea, J. Mar. Syst., 75, 236-244, 2009.

Hunke, E. C. and Dukowicz, J. K.: An elastic-viscous-plastic model for sea ice dynamics, J. Phys. Oceanogr., 27, 1849-1867, 1997.

Hurlburt, H. E., Chassignet, E. P., Cummings, A. B., Kara, A. B., Metzger, E. J., Shriver, J. F., Smedstad, L. F., Wallcraft, A. J., and Barron, C. N.: Eddy-resolving global ocean prediction., in: Eddy-Resolving Ocean Modeling, edited by: Hecht, M. and Hasumi, H., Geophysical Monograph, 177, AGU, Washington DC, 2008.

Johannessen, J. A., Le Traon, P. Y., Robinson, I., Nittis, K., Bell, M. J., Pinardi, N., and Bahurel, P.: Marine environment and security for the European area - Toward operational oceanography, B. Am. Meteorol. Soc., 87, 1081-1090, 2006.

Large, W. G., McWilliams, J. C., and Doney, S. C.: Oceanic vertical mixing - a review and a model with a nonlocal boundary-layer parameterization, Rev. Geophys., 32, 363-403, 1994.

Natvik, L. J. and Evensen, G.: Assimilation of ocean colour data into a biochemical model of the North Atlantic - Part 2. Statistical analysis, J. Mar. Syst., 40, 155-169, doi:10.1016/s09247963(03)00017-4, 2003a.

Natvik, L. J. and Evensen, G.: Assimilation of ocean colour data into a biochemical model of the North Atlantic - Part 1. Data assimilation experiments, J. Mar. Syst., 40, 127-153, doi:10.1016/s0924-7963(03)00016-2, 2003b.

Pasquero, C., Bracco, A., and Provenzale, A.: Impact of the spatiotemporal variability of the nutrient flux on primary productivity in the ocean, J. Geophys. Res.-Oceans, 110, CO7005, doi:10.1029/2004JC002738, 2005.

Reynolds, R. W., Rayner, N. A., Smith, T. M., Stokes, D. C., and Wang, W.: An improved in situ and satellite SST analysis for climate, J. Climate, 15, 1609-1625, 2002.

Sakshaug, E., Bjørge, A., Gulliksen, B., Loeng, H., and Mehlum, F.: Økosystem Barentshavet, Studio Heimdal AS, Trondheim, 1992.

Simon, E. and Bertino, L.: Application of the Gaussian anamorphosis to assimilation in a 3-D coupled physical-ecosystem model of the North Atlantic with the EnKF: a twin experiment, Ocean Sci., 5, 495-510, 2009, http://www.ocean-sci.net/5/495/2009/.

Skogen, M. and Søiland, H.: A user's guide to NORWECOM v2.0. The NORWegian ECOlogical Model system., Institute of Marine Research, Bergen, 42 pp., 1998.

Skogen, M. D., Svendsen, E., Berntsen, J., Aksnes, D., and Ulves- 
tad, K. B.: Modeling the primary production in the North-Sea using a coupled 3-dimensional physical-chemical-biological ocean model, Estuar. Coast. Shelf Sci., 41, 545-565, 1995.

Skogen, M. D. and Moll, A.: Interannual variability of the North Sea primary production: comparison from two model studies, Conti. Shelf Res., 20, 129-151, 2000.

Skogen, M. D., Søiland, H., and Svendsen, E.: Effects of changing nutrient loads to the North Sea, J. Mar. Syst., 46, 23-38, 2004.

Skogen, M. D., Budgell, W. P., and Rey, F.: Interannual variability in Nordic seas primary production, ICES J. Mar. Sci., 64, 889898, 2007.

Smith, S. L., Yamanaka, Y., Pahlow, M., and Oschlies, A.: Optimal uptake kinetics: physiological acclimation explains the pattern of nitrate uptake by phytoplankton in the ocean, Mar. Ecol. Prog. Ser., 384, 1-12, doi:10.3354/meps08022, 2009.

Svendsen, E., Kloster, K., Farrelly, B., Johannessen, O. M., Johannessen, J. A., Campbell, W. J., Gloersen, P., Cavalieri, D., and Matzler, C.: Norwegian remote sensing experiment: Evaluation of the Nimbus 7 scanning multichannel microwave radiometer of sea ice research, J. Geophys. Res.-Oceans Atmos., 88, 2781$2791,1983$.
Teague, W. J., Carron, M. J., and Hogan, P. J.: A comparison between the Generalized Digital Environmental Model and Levitus climtologies, J. Geophys. Res.-Oceans, 95, 7167-7183, 1990.

Uppala, S. M., Kallberg, P. W., Simmons, A. J., Andrae, U., Bechtold, V. D., Fiorino, M., Gibson, J. K., Haseler, J., Hernandez, A., Kelly, G. A., Li, X., Onogi, K., Saarinen, S., Sokka, N., Allan, R. P., Andersson, E., Arpe, K., Balmaseda, M. A., Beljaars, A. C. M., Van De Berg, L., Bidlot, J., Bormann, N., Caires, S., Chevallier, F., Dethof, A., Dragosavac, M., Fisher, M., Fuentes, M., Hagemann, S., Holm, E., Hoskins, B. J., Isaksen, L., Janssen, P., Jenne, R., McNally, A. P., Mahfouf, J. F., Morcrette, J. J., Rayner, N. A., Saunders, R. W., Simon, P., Sterl, A., Trenberth, K. E., Untch, A., Vasiljevic, D., Viterbo, P., and Woollen, J.: The ERA-40 re-analysis, Q. J. Roy. Meteorol. Soc., 131, 2961-3012, 2005.

Winther, N. G. and Evensen, G.: A hybrid coordinate ocean model for shelf sea simulation, Ocean Modell., 13, 221-237, 2006. 